\title{
Analyzing methods of determining pre-destruction of blast hole vicinity
}

\section{Un análisis de los métodos de definición de destrucción preliminar de los alrededores de las perforaciones explosivas}

\author{
Yevgeny B. Shevkun ${ }^{1}$, Alexander V. Leshchinsky ${ }^{1,{ }^{*}}$, Evgeny A. Shishkin ${ }^{1}$, Yuri A. Lysak ${ }^{2}$, \\ Andrey Yu. Plotnikov ${ }^{2}$ \\ ${ }^{1}$ Pacific State University, Khabarovsk, Russian Federation \\ ${ }^{2}$ AVT-Amur LLC, Blagoveshchensk, Russian Federation \\ *000399@pnu.edu.ru
}

(recibido/received: 01-junio-2021; aceptado/accepted: 27-julio-2021)

\begin{abstract}
The level of deformation of the rock massif of a blasted slab must be planned in advance, depending on the required results of blasting. Thus the energy costs of barren rock overfilling as part of preparing for overburden excavation are inefficient. On the contrary, an increase in the blast energy spent on degrading and breaking the ore mass is an efficient measure of preparing for the excavation of mineral wealth. There are currently two methods used to determine the pre-destruction of a blasted rock massif. The first one is based on determining the number of strain waves passing through locations of borehole charges. However, this method fails to determine the preliminary rock destruction level. The second method is based on determining coefficients of the pre-destruction of a rock massif by these strain waves. The merit of this method is that it allows evaluating the quality pattern of the predestruction of a rock massif. The procedure of considering the fraction of energy of the strain waves, reflected by the shielding rock mass to the destructive amount of blasting charges and refracted to this destroyed rock, is proposed.
\end{abstract}

Keywords: Rock deformation; Pre-destruction; Strain wave.

\section{RESUMEN}

La cantidad de deformación del macizo rocoso del bloque volado debe planificarse previamente en función de los resultados requeridos de la voladura. Por ejemplo, en la preparación de la extracción de la roca de sobrecarga, el gasto de energía para volver a moler la roca residual es irracional. Pero en la preparación para la excavación de minerales, que posteriormente serán triturados para su beneficio, es racional aumentar la energía de la explosión en la trituración y el aplastamiento de la masa de mineral. Actualmente, se utilizan dos métodos para determinar la destrucción preliminar de una masa rocosa explotada. El primer método se basa en la determinación de la cantidád de las ondas de tensión que atraviesan las zonas de carga de los pozos. Sin embargo, este método no determina el volumen de destrucción preliminar de la roca. El segundo método se basa en determinar el valor de los coeficientes de prefractura del macizo rocoso a partir de estas ondas de tensión. La ventaja de este método es la posibilidad de estimar una imagen cualitativa de la prefractura del macizo rocoso. Proponemos un método para contabilizar la proporción de energía de las ondas de tensión reflejadas desde la masa de roca de blindaje en el volumen de destrucción de las cargas explosivas, y refractadas en esta roca volada.

Palabras clave: Deformación de la roca; Destrucción preliminar; Onda de tensión. 


\section{INTRODUCTION}

The destruction of subsurface rock is characterized by one kind of destruction, namely, tearing under the influence of stretching stresses due to the activity of compression waves in the rarefaction phase. This results in the formation of systems of cracks covering a rock massif (Fu et al., 2015; Snitka et al., 2015). The quality indicators of explosions using nonelectric initiation systems is characterized by a compact-shaped shotpile, which facilitates the reduction in losses and mining dilution; improved face toe reaming and weaker seismic effect. In work (Rubtsov \&Yershov, 2005) the improvement in these indicators is explained by the multiple explosive loading of rock massif at well-after-well blasting with long delays (150 ms and longer), which facilitates the formation of additional exposed surfaces and increases the number of debris flow concussions.

A lot of complicated issues have been resolved over the past few years thanks to the focused attention of blasting work researchers, engineers, and practitioners to studying the physical basics of the action of mineable explosions in subsurface rock, improving the technology and creating engineering methods of explosion energy management. One of the lines of research includes millisecond blasting works, blasting without a compensatory slot, with interhole retardation, etc. (Leshchinskii et al., 2019; Norov \& Ochilov, 2016; Wua et al., 2015).

A coyote blast project must include a preplanned level of deformation of the rock massif of an exploded slab, depending on required explosion results. Thus the energy costs of barren rock overfilling as part of preparing for overburden excavation are inefficient - the biggest size of exploded rock mass pieces must make it possible to extract them with a shovel dipper. In this case it will be enough to ensure pre-destruction intensity coefficient $K_{u}$ of 1 (Shtukarin, 2010). However, when preparing for the excavation of mineral wealth that will be crushed at enriching, it is rational to increase the explosion energy for ore mass breaking and milling because the breaking of ore in crushing units and, especially its milling in mill pits are incommensurably more energy-intensive.

\section{MATERIALS AND METHODS}

There are currently two methods proposed for determining the pre-destruction of a blasted rock massif. The first one is based on determining the number of strain waves passing through borehole charge locations (Mosinets, 1976). The second one is based on determining the intensity coefficients of the pre-destruction of this massif by strain waves (Shtukarin, 2010).

Let us consider the application of the first method by the example of a huge blast organized on November 20, 2020, in the Central plot of the Malomyr mine site by retarding the surface network of 400x200 ms. Nine hundred and forty wells of $215 \mathrm{~mm}$ in diameter and $6.1 \mathrm{~m}$ in average depth were blasted at an average cutting depth of $5.5 \mathrm{~m}$. The wells were arranged in 110 rows in a $5 \times 5 \mathrm{~m}$ array, with six to twenty wells in a row. The blasted slab volume was $129,015 \mathrm{~m}^{3}$. The specific powder factor was $0.94 \mathrm{~kg} / \mathrm{m}^{3}$. The explosive material consumption was $122,905 \mathrm{~kg}$, including $122,200 \mathrm{~kg}$ of Nitronit E-70.

In the first part of the slab there were up to 20 wells in a row, whereas in the middle and by the end of the slab there were 16 and 12 wells in a row, respectively. The blast pattern was as follows: the slowdowns between the blasts of neighboring wells in a row were $200 \mathrm{~ms}$, and the slowdowns between the blasts in neighboring rows were $400 \mathrm{~ms}$. The slab length of more than half a kilometer does not allow showing it in the visible figure. This is why, it should be indicated only that the bench slope is situated to the left of the starting point in the course of the coyote blast. A region of 15 rows with 12 wells in each was distinguished for the theoretical analysis of the coyote blast evolution pattern.

The well hole charge blast energy crushes the subsurface rock in the destruction zone at a level of up to $40 \mathrm{R}_{\text {crg }}$ and results in the pre-destruction in the rock mass with a size up to $250 \mathrm{R}_{\text {crg }}$ (Aleksandrov et al., 1987; Mosinets, 1976). 
The destruction and pre-destruction radii used to build the blast evolution layout are $35 \mathrm{R}_{\text {crg }}(3.7 \mathrm{~m})$ and $250 \mathrm{R}_{\text {crg }}(26.7 \mathrm{~m})$. Thus the pre-destruction zone radius is fivefold larger than the well array of wells. The conditions accepted for drawing the plot to analyze the passage of strain waves through the borehole charge locations are as follows:

- the destruction zone of each preceding borehole charge blasted with an actual delay of more than 75 $\mathrm{ms}$ is the sealing medium that reflects from its surface to the blasted volume up to a sixth of the strain wave energy and absorbs 60-70 \% of this energy (Shevkun et al., 2017). This is why, the predestruction zone in the vicinity of earlier blasted borehole charges is closed with the beams going from the center of the blasted charge tangentially to the immediate neighboring destruction zones;

- when the pre-destruction zones shaped by simultaneously blasted charges superimpose on the location of some borehole charge, it becomes exposed to all inbound strain waves (in this case, they number up to five, considering the pre-destruction zone/well array size ratio), whatever the direction from which the wave comes - this conditions the occurrence of alternating and multidirectional effects.

The second method is based on determining the values of coefficients of the pre-destruction of the rock massif by these strain waves.

The destruction of subsurface rock by blasting has been studied by a lot researchers (Akande \& Lawal, 2013; Momeni et al., 2015). Considering everything achieved, the blast's influence on subsurface rock is considered as the brittle failure of a resilient flat medium - a plane problem the solution of which is elaborated to the determination of a required unit explosive consumption (Shtukarin, 2010). Since a charge is several times greater in length than in diameter and the displacement in the rock caused by the borehole charge are axially symmetrical, it is proposed to determine the kind of the charge action by solving a plane (2D) problem (Shevkun et al., 2018; Sukhanov et al., 1958). The strain wave spreads beyond the blast cavity borders to preliminarily destruct the vicinity of the surrounding borehole charges. The deformation (pre-destruction) of the vicinity of these wells is determined as

$$
\varepsilon_{i}=\varepsilon_{\text {mp }} K_{\text {и }}=\varepsilon_{\text {mp }}\left(\frac{r}{R_{i}}\right)^{2},
$$

where $\varepsilon_{i}$ is the deformation level of the vicinity of an $i^{\text {th }}$ well; $K_{u}$ is the pre-destruction intensity coefficient taking into account the change in the massif's deformation with an increasing distance from the blasted well axis;

$r$ is the radius of the zone destroyed by the borehole charge;

$R_{i}$ is the distance between the axes of the $i^{\text {th }}$ and the blasted well.

When explosion chamber deformation limit $\varepsilon_{\text {lim }}$ is attained, coefficient $K_{u}$ is equal to one, that is, the well's explosion chamber is fully destroyed. The application of this method will be considered by the example of the same coyote blast in the Central plot of the Malomyr opencast with a delay of $400 \mathrm{x}$ $200 \mathrm{~ms}$. The blast was organized on November, 2020.

\section{RESULTS AND DISCISSION}

The results of using the first method to determine the pre-destruction of a blasted rock massif are shown in Fig. 1. This method consists in counting the number of strain waves that propagate from the blasts of surrounding wells through the vicinity of a borehole charge located in the section considered at this moment. The number of a borehole charge is shown above the circle that indicates this charge; the delay in response from the beginning of the blast is indicated under the circle; the total number of strain waves that have passed through the location of the borehole charge by the time of its response is shown within the circle. 


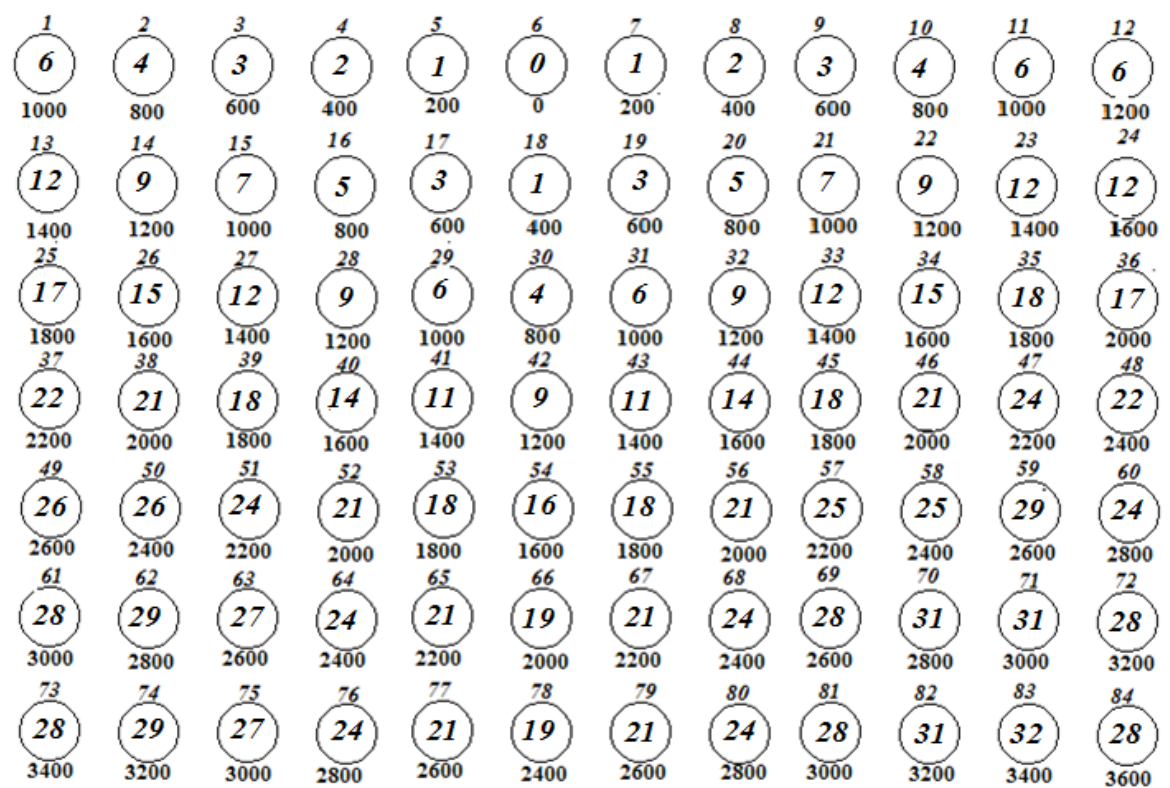

Figure 1. Graphical analysis of the passing of strain waves through borehole charge locations in a selected site

The results of using the second method to determine the pre-destruction of a blasted rock massif are shown in Fig. 2. This method consists in determining the total pre-destruction intensity coefficient by summing the coefficients of pre-destruction from the blasts or surrounding wells. The number of a borehole charge is shown above the circle that indicates this charge; the delay in response from the beginning of the blast is indicated under the circle; the aggregate intensity coefficient of the predestruction of the borehole vicinity by blasting neighboring wells is shown within the circle.

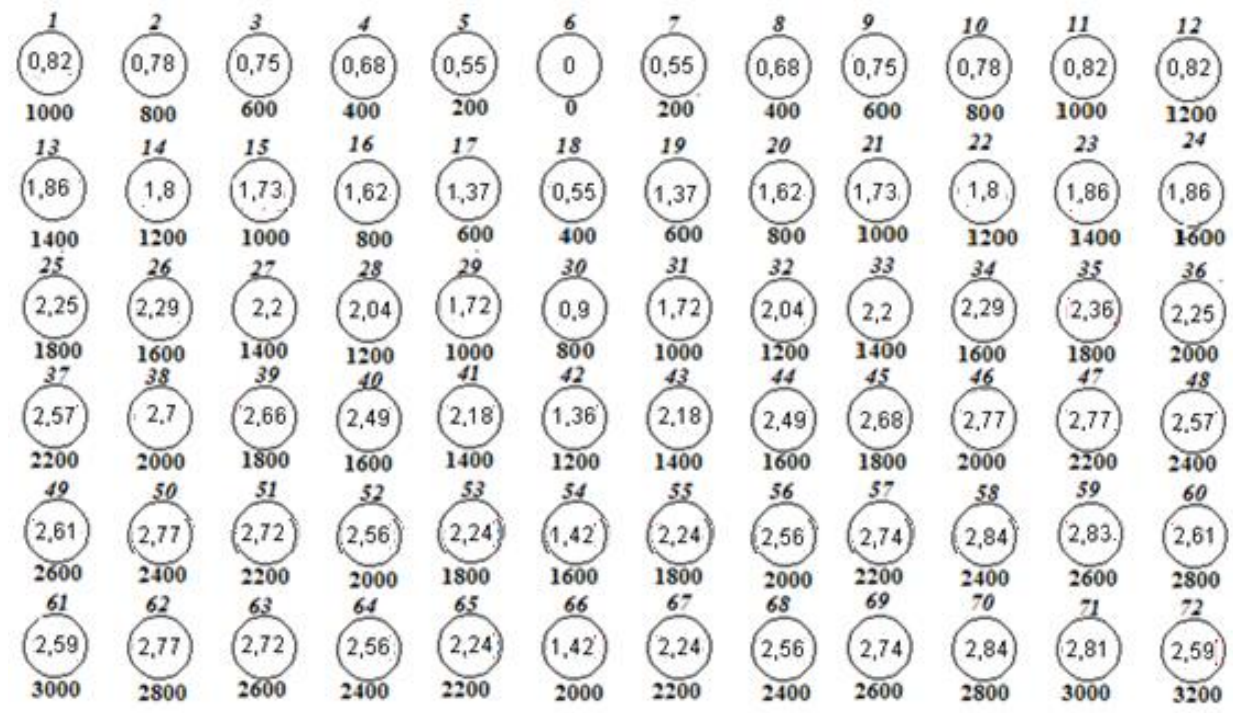

Figure 2. Graphical analysis of the aggregate intensity coefficient of pre-destruction of a borehole's vicinity by blasting neighboring boreholes in a selected site with a $5 \times 5 \mathrm{~m}$ array

The radius of the pre-destruction by the second method is determined according to the plot in Fig. 3 on condition that the minimal accepted pre-destruction intensity coefficient is $0.06(6 \%)$ of the predestruction intensity coefficient of 1 . As seen from the plot, this coefficient goes down very fast with an increase in the distance and is below $5 \%$ of $K_{u}=1$ at $17 \mathrm{~m}$ from the blasted well axis. Thus the actual pre-destruction zone radius is clearly overestimated as compared with recommended radius of $250 \mathrm{R}_{\text {crg }}(26.7 \mathrm{~m})$ and the passing of strain waves through emote borehole charge locations does not produce the necessary rock pre-destruction. 


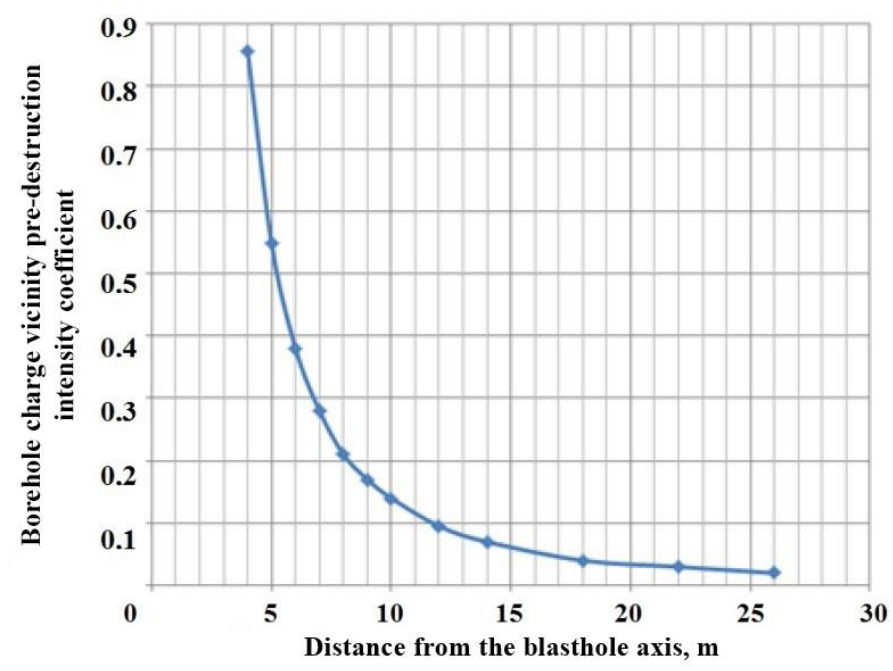

Figure 3. Dependence of the pre-destruction intensity coefficient on the distance between the axes of the blasthole and the $i^{\text {th }}$ well

It follows from Fig. 2 that, with this blasting pattern and borehole charges positioned in a $5 \times 5 \mathrm{~m}$ array, the value of pre-destruction intensity coefficient $K_{u}$ gradually increases to the sixth row of wells and then stabilizes and exceeds by 42 to $184 \%$ the value necessary for destroying the massif. Hence, the result blast energy surplus can produce a positive effect only in case of the blast preparation of the ore region, when the rock mass is mechanically crushed and milled at high energy costs.

Now the above exposed assumptions will be used to analyze the evolution of the mass blast in the chosen region.

The number of strain waves, that passed through the borehole charge locations in the slab (see Fig. 1), increases in the cutting row with the evolution of the blast from 1 in row two to 19 in row six and then stabilizes at this level. However, the pattern significantly changes by rows. Since the number of wells (12) in the rows is even and the cutting row is located in the middle, there is certain asymmetry with five charges on the left and six on the right; this results in an interesting effect. In the left and the right parts the respective buildups are from 21 to 24 to 27 to 29 and from 21 to 24 to 28 to 31 to 32 . Thus, considering the low number of borehole charges, the presence of an odd charge significantly changes the strain wave action pattern in the pre-destruction zone.

The differences in the number of strain waves passing through the borehole charge locations are seen already from row three. The cause of this phenomenon is revealed by the graphical analysis of the evolution of the coyote blast at a delay of $2400 \mathrm{~ms}$ (see Fig. 4). 


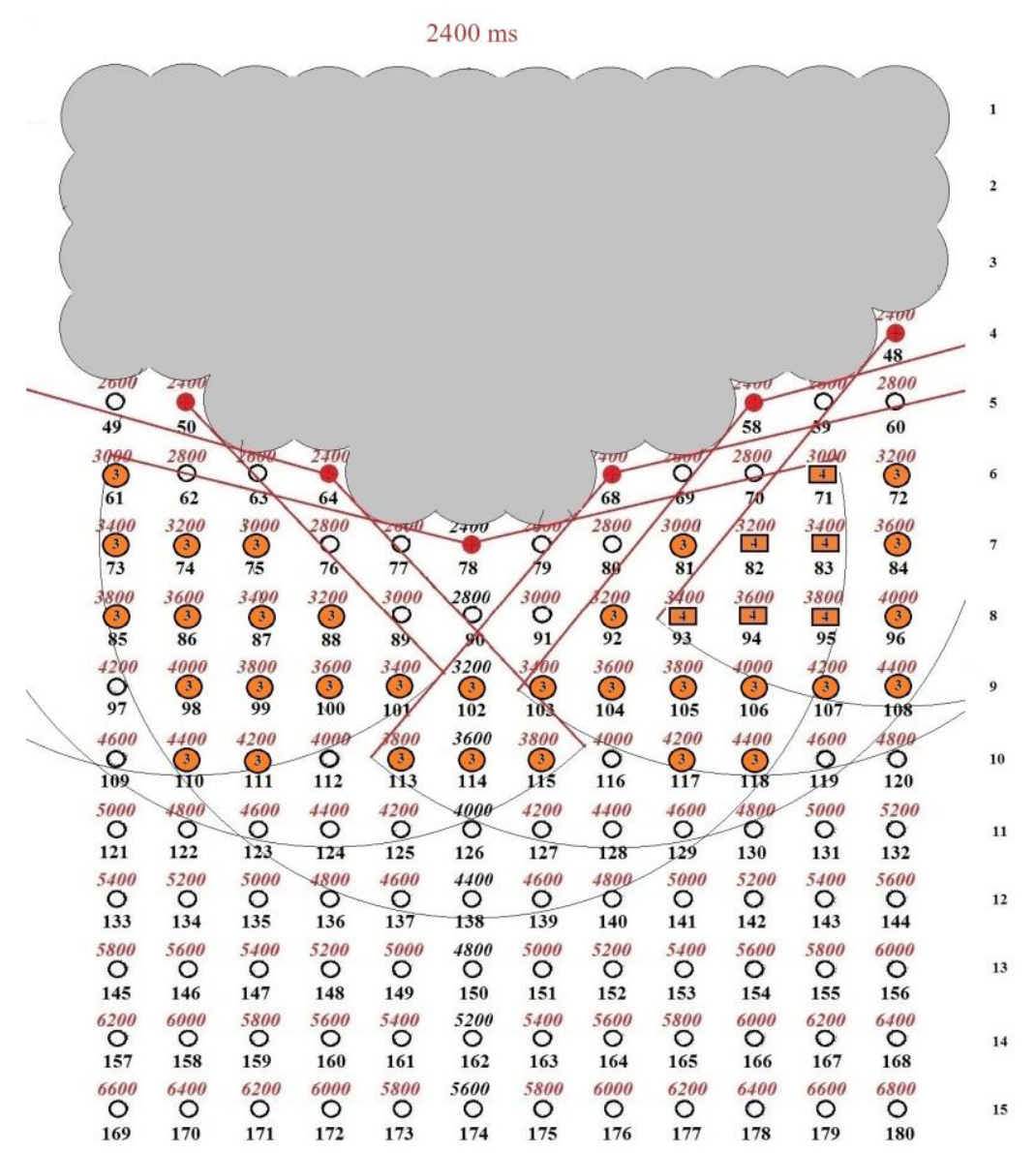

Figure 4. Graphical analysis of the explosion's evolution by the point of $2400 \mathrm{~ms}$

The interaction on the left of the cutting row is seen only between the zones of two borehole charges blasted in rows 5 and 6; even when they interact with the pre-destruction zone of borehole charge 78 of the cutting row, these zones do not provide the quadruple strain wave effect. The quadruple impact of strain waves on the regions of charges $71,82,83$, and 93-95 occurs only in the right part, where it is formed by the pre-destruction zone of the three charges blasted in rows 4-6 in the interaction with the pre-destruction zone of borehole charge 78 of the cutting row.

Thus, even the response of the cutting row charge ensures the quadruple passing of strain waves through the right part of the scheme relative to the cut only in the region of 6 charges.

The pattern shown in Fig. 5 for the next retardation stage of $2600 \mathrm{~ms}$ is even more interesting. The number of borehole charges blasted by this point was sixty three (35\%), with three charges actuated at this stage of retardation on each side of the cut.

It can therefore be stated that it is necessary to have at least five synchronously actuating charges to ensure the successive interaction of strain waves when the pre-destruction zone radius is fivefold larger than the array of wells. 


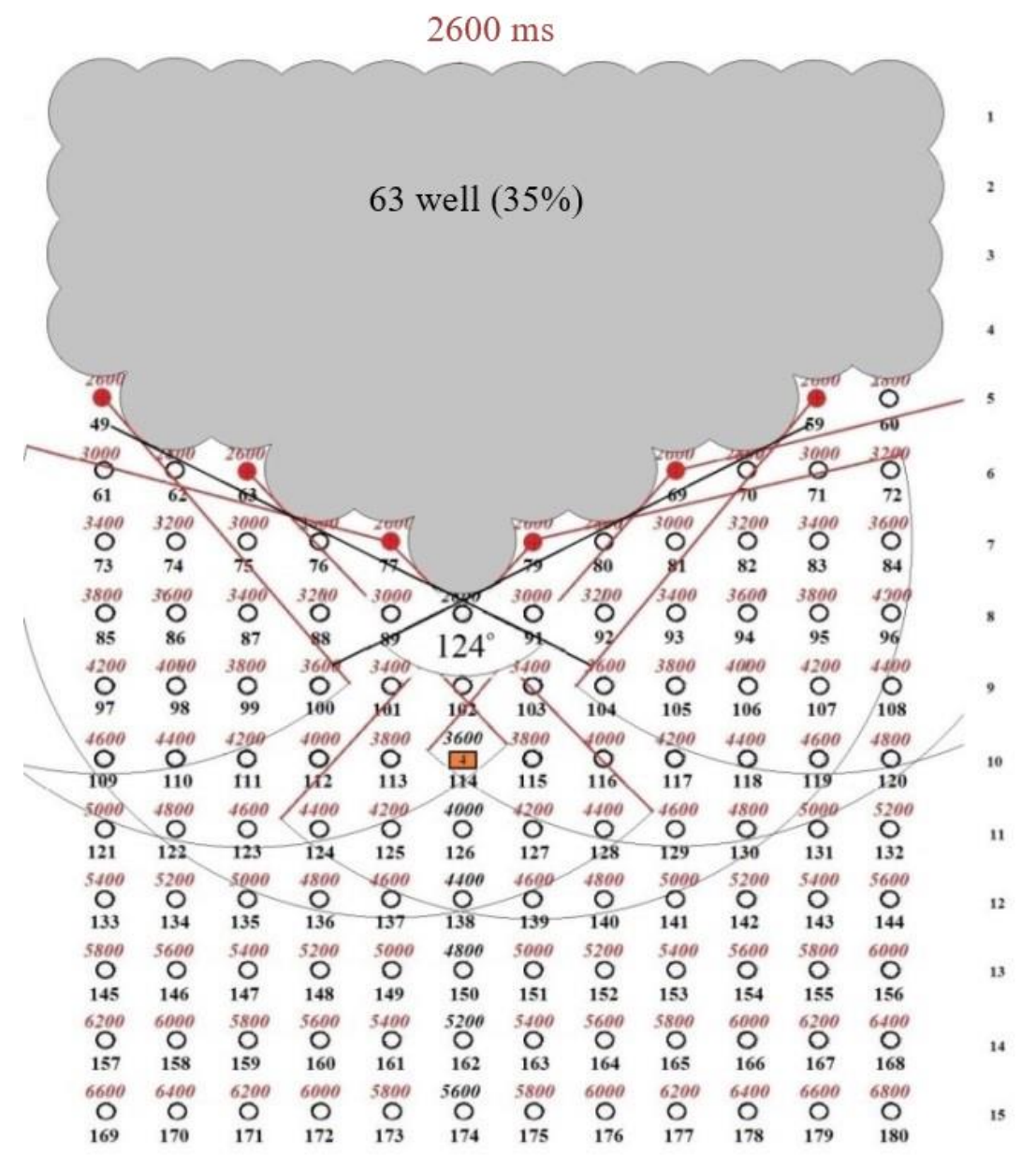

Figure 5. Graphical analysis of the explosion's evolution by the point of $2600 \mathrm{~ms}$

Let us consider another aspect of managing the quality of rock crushing in the course of a coyote blast. One of the key parameters in forming a secondary field of stresses in the medium being destroyed is the acoustic stiffness of the medium adjacent to the external loop of destruction. The difference of this stiffness from the acoustic stiffness of the main massif determines not only the parameters of reflected waves, that affect the efficiency of the shattering effect, but also the parameters of refracted waves, that penetrate this medium. These waves determine the blast's seismic action as the energy of refracted waves is spent on repacking and additionally destroying pieces of the blasted rock mass, which weakens the energy of seismic action. The blast energy management by changing the conditions in the external loop of destruction allows significantly improving the blasted rock mass crushing quality at lower costs. When the strain waves interact with the sealing surface, 30-35\% of their energy are reflected towards the main destruction volume, about $8 \%$ pass beyond the screen to the medium separated by it from the main destruction volume, and 60-70\% are absorbed by the screen (Aleksandrov et al., 1987). The energy that goes away in the opposite direction crushes the subsurface rock in the destruction zone and pre-destructs the rock massif.

Let us use these assumptions to consider the possibilities of improving the quality of crushing and preserving the primary structure of the massif in the shotpile by a set of factors that include stump blasting, shielding the blast energy by destroyed rock mass, and increasing the massif fracturing in the predestruction zone. In addition to changing the parameters of reflected strain waves, stump blasting in the form of blasted rock mass along the external loop of destruction allows redistributing the kinetic energy of outbreak to the energy of crushing. The strain waves, that are reflected by the subsurface rock as by the shielding medium destroyed by the blasts of previous charges, increase the fraction of blast energy in the rock volume destroyed by a specific charge. The strain waves refracted to the de- 
stroyed medium additionally increase its crushing degree: the sufficient contractibility of the destroyed rock guarantees the high-quality of crushing while using the kinetic energy of outbreak on this process (Aleksandrov et al., 1987).

The multiple passing of strain waves in the contraction-extension stage through the blasthole charge vicinity in the pre-destruction zone significantly increases the jointing of the rock massif and favours its fissuring into finer fractions.

In case of the blasting in the one-spacing-per-well pattern the reflecting shield is the zone of the rock destruction by the preceding charge blasted at least for $75 \mathrm{~ms}$. This is an essential prerequisite for, as shown by study (Aleksandrov et al., 1987), the distance to the shielding surface must be as short as possible so as the fronts of the transversal and longitudinal waves from the blasted charge would not be able to diverge for these waves are absorbed by the destroyed rock in different ways and the shield located at a large distance is bended round by these waves without major changes. In our case the zone destructed from the preceding charge is tightly located and is an ideal shielding surface; however, it must have enough time for shaping, which is why the next blast must be made at least after a hundred $\mathrm{ms}$, considering the deviation of the retarders from nominal.

The deviations allowed by the system's manufacturer Rionel for surface retarders of $200 \mathrm{~ms}$ are \pm 12.5 $\mathrm{ms}$, whereas the actuation range of borehole retarders with a nominal value of $750 \mathrm{~ms}$ is from 725 to $800 \mathrm{~ms}$. Then the combination of the surface retarder of $200 \mathrm{~ms}$ and the borehole retarder of $750 \mathrm{~ms}$ can actuate at the maximal nominal deviations after 163 or $262 \mathrm{~ms}$, actually with a gap of $100 \mathrm{~ms}$. To ensure a delay of $400 \mathrm{~ms}$ for the cutting row, it was necessary to sequentially connect two retarders of $200 \mathrm{~ms}$; the maximal nominal deviation may reach 150 to $275 \mathrm{~ms}$, whereas the gap goes up to $125 \mathrm{~ms}$. Hence, the guaranteed gap in delays ensured by the Rionel nonelectric system with the 200x400 ms pattern is $100 \mathrm{~ms}$.

As established earlier in (Shevkun et al., 2017), the crushing quality is significantly improved and the rock mass displacement decreased at delay intervals extended from 42-67 to 150-200 ms. However, the blasting pattern with $150 \times 200 \mathrm{~ms}$ intervals does not allows efficiently using the blasted rock mass as a shield for the interval between borehole charge blasts is $50 \mathrm{~ms}$ against $75 \mathrm{~ms}$ necessary to form the shield.

It is seen in Fig. 4 that there occurs the synchronous actuation of the double set of three wells 50,64 and 78 to the left of the cut and four wells 48, 58, 68 and 78 to the right of it. All of them but for well 78 are surrounded on three sides with the shield of destroyed rock, which allows reflecting some part of the strain wave energy of each blasted charge to the rock volume destroyed by it. For the pattern of the interaction with the shielding surface of strain waves from the set of charges to the right of the cut in the delay stage of $2400 \mathrm{~ms}$, see Fig. 6.

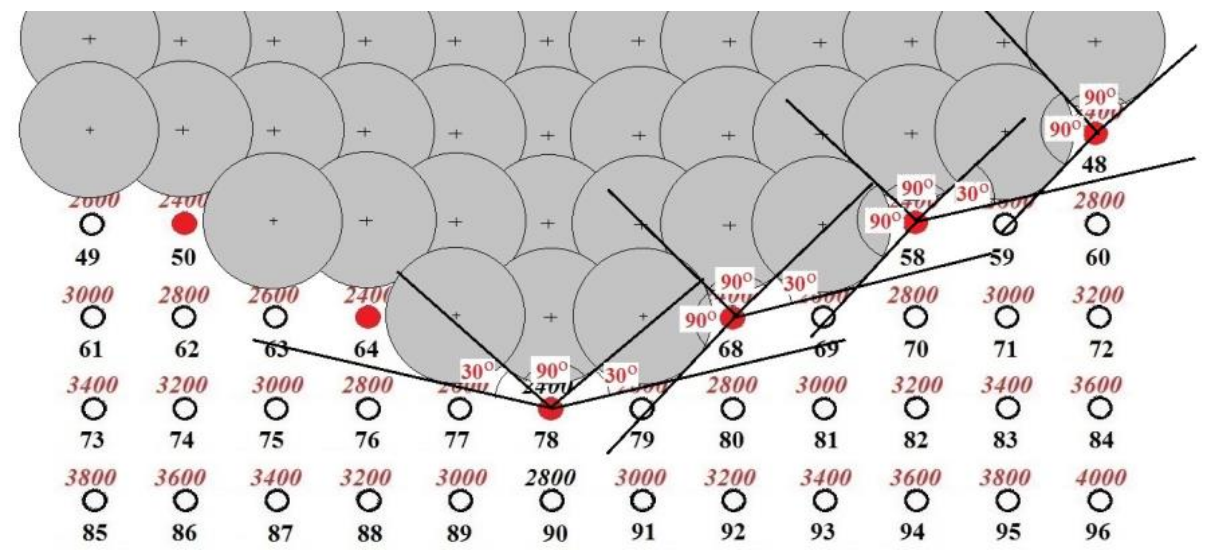

Figure 6. Strain waves from charges to shielding surfaces 
The strain wave from borehole charge 78 interacts with the rock volume earlier destroyed by borehole charge 66 in the sector at an angle of roll of $150^{\circ}$, where $42 \%$ of the wave's energy are spent. Hence, according to (Aleksandrov et al., 1987), a third of this energy will be reflected from the destroyed rock as from a shield and the other two thirds will be refracted to the destroyed volume. The remaining energy confined to the sector with an angle of roll of $210^{\circ}$ will do the crushing in the destruction zone and cracking in the pre-destruction zone in which case the additional energy of the wave reflected from the shield will also be used to crush the rock.

These prerequisites were used to calculate the fraction of the energy of strain waves that are reflected from the shield rock mass into the volume, destroyed by the charge blasting to the right of the cut, and refracted to this destroyed rock (Table 1).

Table 1. Fraction of energy of strain waves from blasted charges, $\%$

\begin{tabular}{|c|c|c|c|c|c|c|c|c|c|}
\hline \multirow{4}{*}{$\begin{array}{l}\text { Blasted } \\
\text { charge }\end{array}$} & \multicolumn{9}{|c|}{ Fraction of energy of strain waves from blasted charges, $\%$} \\
\hline & \multirow{3}{*}{$\begin{array}{l}\text { crushing } \\
\text { and pre- } \\
\text { destructi } \\
\text { on }\end{array}$} & \multicolumn{8}{|c|}{$\begin{array}{l}\text { Reflection to the destroyed amount/refraction to the rock mass shield } \\
\text { ing the blasted charge }\end{array}$} \\
\hline & & \multicolumn{8}{|c|}{ Borehole charge numbers } \\
\hline & & 36 & 46 & 47 & 56 & 57 & 65 & 66 & 67 \\
\hline 48 & $50+16$ & $8 / 17$ & & $8 / 17$ & & & & & \\
\hline 58 & $42+18$ & & $8 / 17$ & $2 / 6$ & & $8 / 17$ & & & \\
\hline 68 & $42+18$ & & & & $8 / 17$ & $2 / 6$ & & & $8 / 17$ \\
\hline 78 & $72+13$ & & & & & & $2 / 6$ & $8 / 17$ & $2 / 6$ \\
\hline Total & & $8 / 17$ & $8 / 17$ & $10 / 23$ & $8 / 17$ & $10 / 23$ & $2 / 6$ & $8 / 17$ & $10 / 23$ \\
\hline
\end{tabular}

For the design rates of the energy of the strain waves refracted from the blasting charges to the rock destroyed by preceding blasts for all of the wells at the delay stage of $2400 \mathrm{~ms}$, see Fig. 7 .

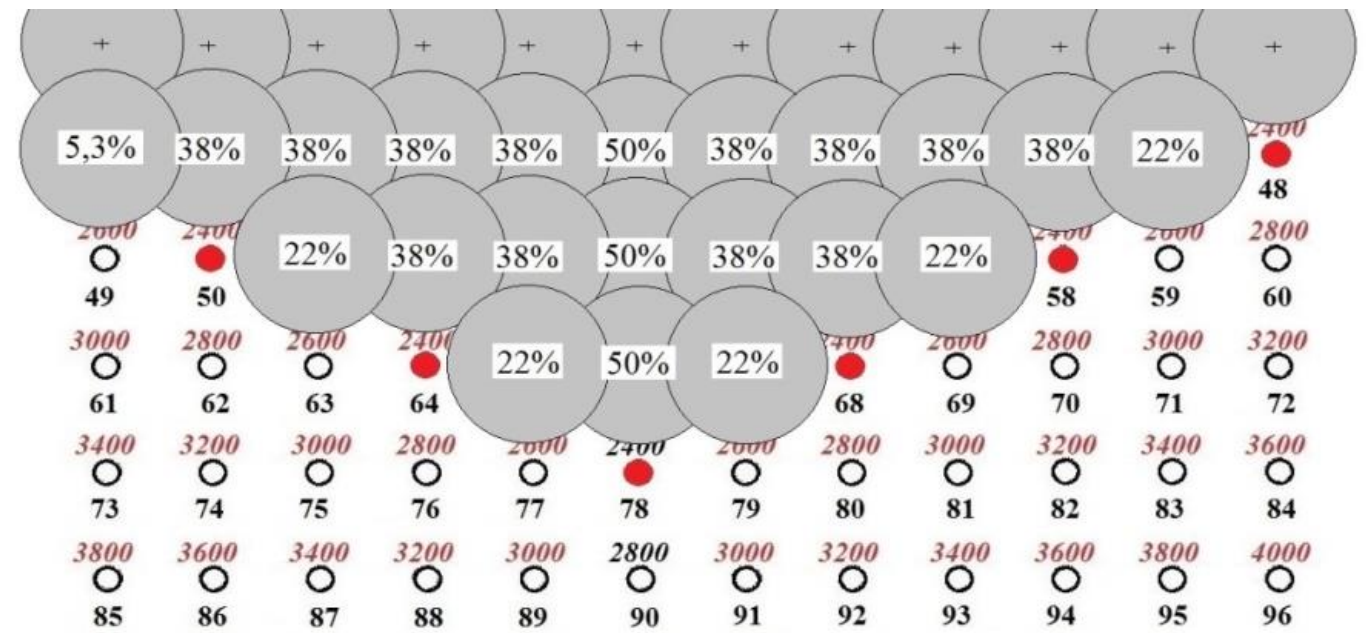

Figure 7. Additional strain wave energy refracted to destroyed rock

Let us consider the parameters of weakening the rock massif in the pre-destruction zone and the impact of the energy of reflected and refracted strain waves, for example, in the destruction zone of barren rock, considering that the borehole charges are arranged in an $8 \times 8 \mathrm{~m}$ array. For the parameters of the strain waves at the delay stage of $2400 \mathrm{~ms}$, see Fig. 8 . 


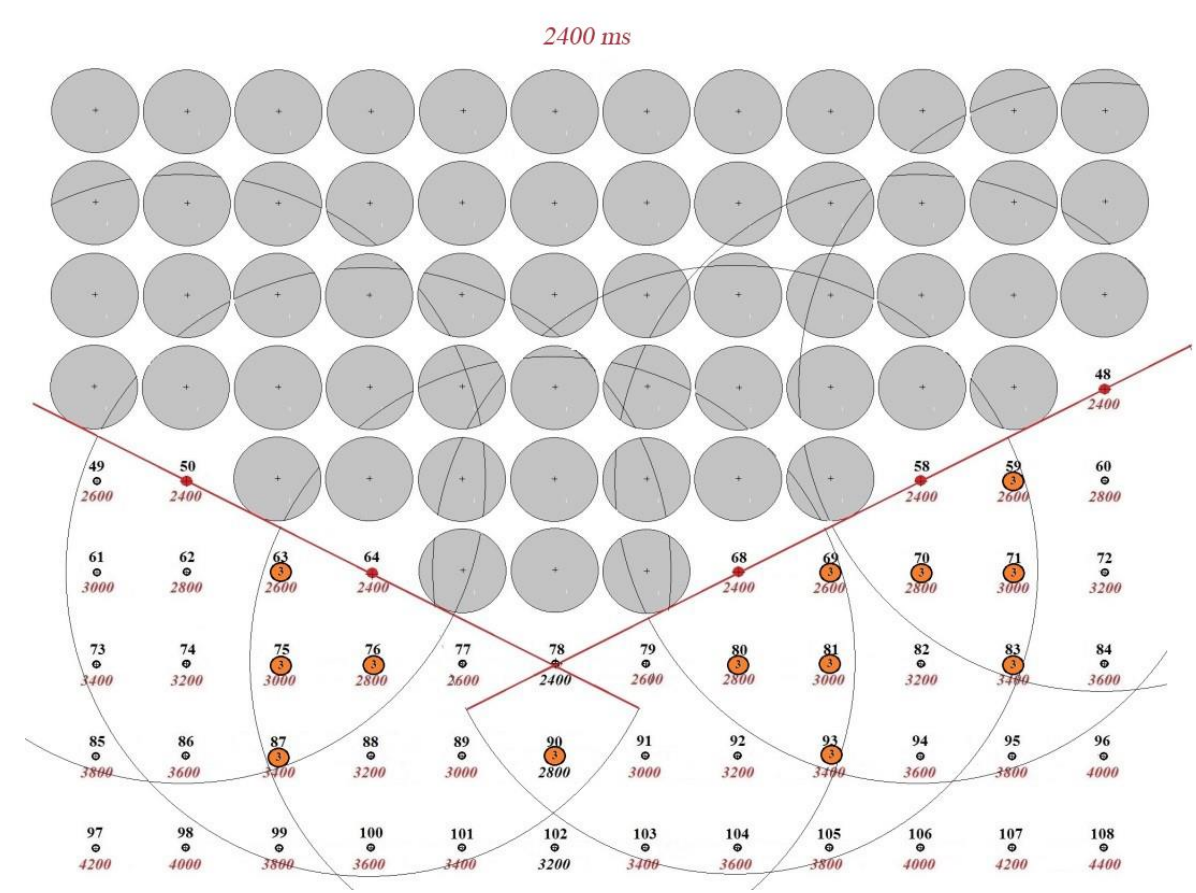

Figure 8. Graphical analysis of the explosion's evolution by $2400 \mathrm{~mm}$ in an $8 \times 8 \mathrm{~m}$ array

It is seen in Fig. 8 that at this stage of delay 44 borehole charges are located in the pre-destruction zone. The strain waves from the blast of 6 charges passed through the region of 39 charges and did it thrice only for 13 charges. At the same time, 24 such cases occurred for the charges arranged in a $5 \times 5$ $\mathrm{m}$ array, and the region of 6 charges was passed by the strain waves four times.

For the intensity coefficients of the pre-destruction of the slab wells' vicinity by blasting the neighboring wells, with the borehole charges arranged in an $8 \times 8 \mathrm{~m}$ array, see Fig. 9. It is seen that, with the borehole charges placed in this manner, the strain wave impact energy gradually rises to the fourth row of wells and then stabilizes and does not exceed the value of one necessary for destroying the massif. Hence, it is possible to cut the costs of drilling and spending explosives while preserving the rock mass crushing quality.

Valuable ore mining makes it necessary to retain as much as possible the natural contacts of ore zones with barren rock and decrease the mixing of rock mass while preparing it for excavation by blasting loosening.

This is attained by special blasting methods. This is why, the theoretical and practical research of rock breaking by borehole charges are continued, including physical and mathematical modeling (Ghiasi et al., 2016; Duan et al., 2015; Kutuzov \& Tyupin, 2017; Moldovan et al., 2017; Ofoegbu \& Smart, 2019; Silva et al., 2019; Vokhmin et al., 2015; Yan et al., 2015). The blasting for a buffer of earlier blasted rock mass or the blasting in an absolutely pressed medium (for monolithic massif) have become widespread practices in open-cut mining. This blasting allows managing the shotpile and conducting selective excavation.

At delays to $100 \mathrm{~ms}$ the average blast rock mass displacements range from 2.6 to $6.5 \mathrm{~m}$ and the shotpile has an uneven surface with large variations in elevation points. At delays of 150 to $200 \mathrm{~ms}$ the average rock mass displacements ranges from 2 to $4 \mathrm{~m}$ and the shotpile surface is smoother. At delays extended to 275-300 ms the average displacement of the blasted rock mass went down to 1.1-1.8 m. The shotpile had an even surface without sharp variations in elevation points. The decrease in the horizontal displacement of the blasted rock mass to 1-2 $\mathrm{m}$ at delays of 275-300 ms allows carrying to the shotpile surface the borders of the local mineralization region while extended the loop size by $1-2 \mathrm{~m}$. 


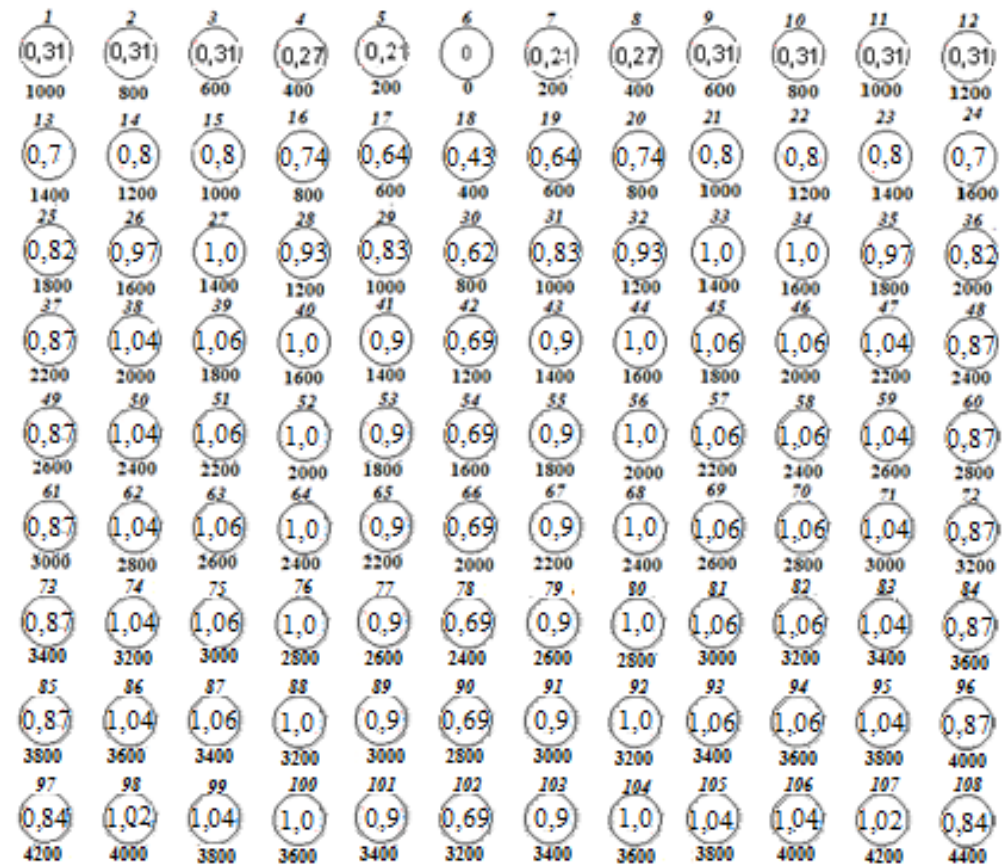

Figure 9. Graphical analysis of the pre-destruction of a rock massif at the passing of strain waves through borehole charge locations in an $8 \times 8 \mathrm{~m}$ array

\section{CONCLUSION}

The strength of determining the pre-destruction of $\mathrm{BH}$ vicinity on the basis of identifying the number of strain wave passes through borehole charge locations is simplicity. The layout of an exploded slab contains a circle drawn for each exploded charge with a specified pre-destruction radius. The number of BHs is counted that are included in a highlighted area of the circle.

However, the method based on determining the number of strain waves passing through borehole locations does have drawbacks. The intensity with which these waves pass through a considered location is unclear. It is impossible to sum the number of strain waves and the fraction of the energy of these waves reflected by the sealing run-of-mine to the destructive amount of exploding charges and refracted to this destroyed rock.

Although the fraction of this energy is calculated, it is impossible to sum the number of strain waves and this fraction of energy.

The strength of the second method based on determining the coefficients of the pre-destruction of a rock massif by these strain waves is that it allows evaluating the quality pattern of the pre-destruction of a rock massif in each point of the exploded slab. This procedure allows considering fractions of energy of the strain waves reflected by the sealing run-of-mine to the destructive amount of exploding charges and refracted to this destroyed rock. It is shown that the adjustment of borehole array parameters allows using the changes in the preliminary rock destruction level to save material and financial resources while maintaining a high quality of crushing.

\section{REFERENCIAS}

Akande, J. M., and Lawal, A. I. (2013). Optimization of Blasting Parameters Using Regression Models in Ratcon and NSCE Granite Quarries, Ibadan, Oyo State, Nigeria. Geomaterials, 3(1), 28-37. 
Aleksandrov, V. E., Kochanov, A. N., \& Levin, B. V. (1987). On interconnection of strength and acoustic properties of rock in the pre-destruction explosive action zone. Journal of Mining Science, 145(23), No. 4, 24-32.

Duan, Y., Xiong, D., Yao, L., Wang, F., \& Xu, G. (2015). Advanced Technology for Setting Out of Blastholes and Measurement while Drilling. Proceedings of the 11th International Symposium on Rock Fragmentation by Blasting (Fragblast 11), pp. 593-598.

Fu., Xiaodong, Sheng, Qian, Zhang, Yonghui, and Chen, Jian (2015). Application of the discontinuous deformation analysis method to stress wave propagation through a one-dimensional rock mass. International Journal of Rock Mechanics and Mining Sciences, 80, 155-170.

Ghiasi, M., Askarnejad, N., Dindarloo, S., \& Shamsoddini, H. (2016). Prediction of blast boulders in open pit mines via multiple regression and artificial neural networks. International Journal of Mining Science and Technology, 26 (2), 183-186.

Kutuzov, B. N., \& Tyupin, V. N. (2017). Drilling and blasting design method to ensure preset fragmentation of rocks in open pit mining. Gornyi Zhurnal, 8, 66-69.

Leshchinskii, A. V., Shevkun, E. B., \& Lysak, Yu. A. (2019). Effect of direction of initiation of explosive charges on pre-destruction of rock material massif. Mining information and analytical bulletin, 2, $50-57$.

Moldovan, D., Chernobai, V., \& Kovalevskyi, V. (2017). Solving the issue of regulating the granulometric composition of shattered rock mass depending on the quality of locking explosion products in the explosion cavity. International Journal of Mechanical Engineering and Technology, 8(11), 11331142.

Momeni, A., Karakus, M., Khanlari, G. R., \& Heidari, M. (2015). Effects of cyclic loading on the mechanical properties of a granite. International Journal of Rock Mechanics and Mining Sciences, 77, 89-96.

Mosinets, V. N. (1976). Crushing and seismic effects of subsurface rock explosion. Moscow: Nedra.

Norov, Yu. D., \& Ochilov, Sh. A. (2016). Control over rock crushing under the influence of blasting energy of borehole charges of explosives in open-cast mining. Mining Bulletin of Uzbekistan, 4(67), $17-23$.

Ofoegbu, G. I., \& Smart, K. J. (2019). Modeling discrete fractures in continuum analysis and insights for fracture propagation and mechanical behavior of fractured rock. Results in Engineering, 4, 100070.

Rubtsov, S. K., \& Yershov, V. P. (2005). Primeneniye neelektricheskikh sistem initsiirovaniya na karyerakh Navoiyskogo GMK [Application of nonelectric initiation systems in open pits of Navoi MMC]. Proceedings of the $4^{\text {th }}$ International Scientific Conference on Physical Problems of Rock Destruction, pp. 387-391. Moscow: Interagency Commission for Blasting Work at the Academy of Mining Sciences.

Shevkun, E. B., Leshchinskii, A. V., Lysak, Yu. A., \& Plotnikov, A. Yu. (2017). Features of explosive loosening at the increased intervals of delay. Mining information and analytical bulletin, 4, 272-282.

Shevkun, E. B., Leshchinskii, A. V., Shishkin, E. A., \& Lysak, Yu. A. (2018). Graph analytical method of defining the intensity of pre-destruction of blasthole vicinity. Blasting work, 127(78), 33-47.

Shtukarin, N. G. (2010). Explosion physics in applied problems. Krasnoyarsk: Sitall. 
Silva, J., Worsey, T., \& Lusk, B. (2019). Practical assessment of rock damage due to blasting. International Journal of Mining Science and Technology, 29(3), 379-385.

Snitka, N. P., Misliboev, I. T., \& Karimov, Yo. L. (2015). Developing energy-saving technology of drilling-and-blasting operations in the weakness zone of rock massif in deep open pits. Mining Bulletin of Uzbekistan, 2(61), 7-11.

Sukhanov, A. F., Nazarov, P. P., \& Dmitriev, A. P. (1958). Drilling-and-blasting operations. Moscow: Academy of Sciences of the Soviet Union.

Vokhmin, S. A., Kurchin, G. S., Kirsanov, A. K., \& Gribanova, D. A. (2015). Review of existing methods determination of zones rock mass destruction. Modern Problems of Science and Education, $1(1)$.

Wua, Bangbiao, Chenc, Rong, \& Xia, Kaiwen (2015). Dynamic tensile failure of rocks under static pre-tension. International Journal of Rock Mechanics and Mining Sciences, 80, 12-18.

Yan, Bo, Zeng, Xinwu, \& Li, Yuan (2015). Subsection Forward Modeling Method of Blasting Stress Wave Underground. Mathematical Problems in Engineering.

\section{SEMBLANCE OF THE AUTHORS}

Evgenii B. Shevkun: He is a Full Doctor of Engineering Sciences, Professor at Federal State Budgetary Educational Institution of Higher Education "Pacific State University". His fields of scientific interests include Geotechnical Engineering and Engineering Geology.

Aleksandr V. Leshchinskii: He is a Full Doctor of Engineering Sciences, Docent, Professor at Department of Transport and Technological Systems in Construction and Mining of Federal State Budgetary Educational Institution of Higher Education "Pacific State University". His fields of scientific interests include Geotechnical Engineering and Engineering Geology.

Evgenii Al. Shishkin: He is a Candidate of Engineering Sciences, Associate Professor at Department of Transport and Technological Systems in Construction and Mining of Federal State Budgetary Educational Institution of Higher Education "Pacific State University". His fields of scientific interests include Geotechnical Engineering and Engineering Geology.

Yurii Al. Lysak: He is a CEO of AVT-Amur LLC. His fields of scientific interests include Geotechnical Engineering and Engineering Geology.

Andrei Yur. Plotnikov: He is an Assistant Chief Engineer in Drilling and Blasting of AVT-Amur LLC. His fields of scientific interests include Geotechnical Engineering and Engineering Geology. 